\title{
Microbial Colonization Promotes Model Invertebrate Gut Tissue Growth and Development
}

\section{Benjamin C Jahnes}

The Ohio State University

\section{Keshap Poudel}

The Ohio State University

Amelia Staats

The Ohio State University

\section{Sophia Nicholas}

The Ohio State University

\section{ZAKEE L SABREE ( $\sim$ SABREE.8@OSU.EDU)}

Ohio State University Foundation: The Ohio State University https://orcid.org/0000-0001-9310-1641

\section{Research}

Keywords: Digestive tissues, Periplaneta americana cockroach, filial coprophagy and exuvia feeding

Posted Date: February 8th, 2021

DOI: https://doi.org/10.21203/rs.3.rs-164026/v1

License: (c) (1) This work is licensed under a Creative Commons Attribution 4.0 International License. Read Full License 


\section{Abstract}

BACKGROUND. Digestive tissues are essential for diet processing and nutrient accessibility, especially in omnivores, and these functions occur despite and in collaboration with dynamic microbial communities that reside within and upon these tissues. Prolonged host development and reduced digestive tissue sizes have been observed in germ-free animals and normal host phenotypes were recovered following the reintroduction of typical gut microbiomes.

RESULTS. High-resolution histological analyses of Periplaneta americana cockroach digestive tissues revealed that total elimination of gut bacteria had severe impacts on the growth and development of gut tissues, especially the posterior midgut and anterior hindgut subcompartments that are expected to be colonized and inhabited by the greatest number of bacteria. Juveniles that were briefly exposed to normal gut microflora exhibited a partial gut morphological recovery, suggesting that a single inoculation was insufficient. These data highlight gut microbiota as integral to normal growth and development of tissues they are in direct contact with and, more broadly, the organism in which they reside.

CONCLUSIONS. We draw on these data, integrate host life history traits (i.e. multigenerational cohousing, molting, and filial coprophagy and exuvia feeding), and previous studies to propose a host developmental model in which gut tissues reflect a conflict-collaboration dynamic where 1) nutrient-absorptive anterior midgut tissues are in competition with transient and resident bacteria for easily assimilable dietary nutrients and whose growth is least-affected by the presence of gut bacteria and 2) posterior midgut, anterior hindgut, and to a lesser degree, posterior hindgut tissues are significantly impacted by gut bacterial presence because they 46 are occupied by the greatest number of bacteria and the host is relying upon, and thus collaborating with, them to assist with complex polysaccharide catabolism processing and nutrient provisioning (i.e. short-chain fatty acids).

\section{Full Text}

This preprint is available for download as a PDF.

\section{Figures}



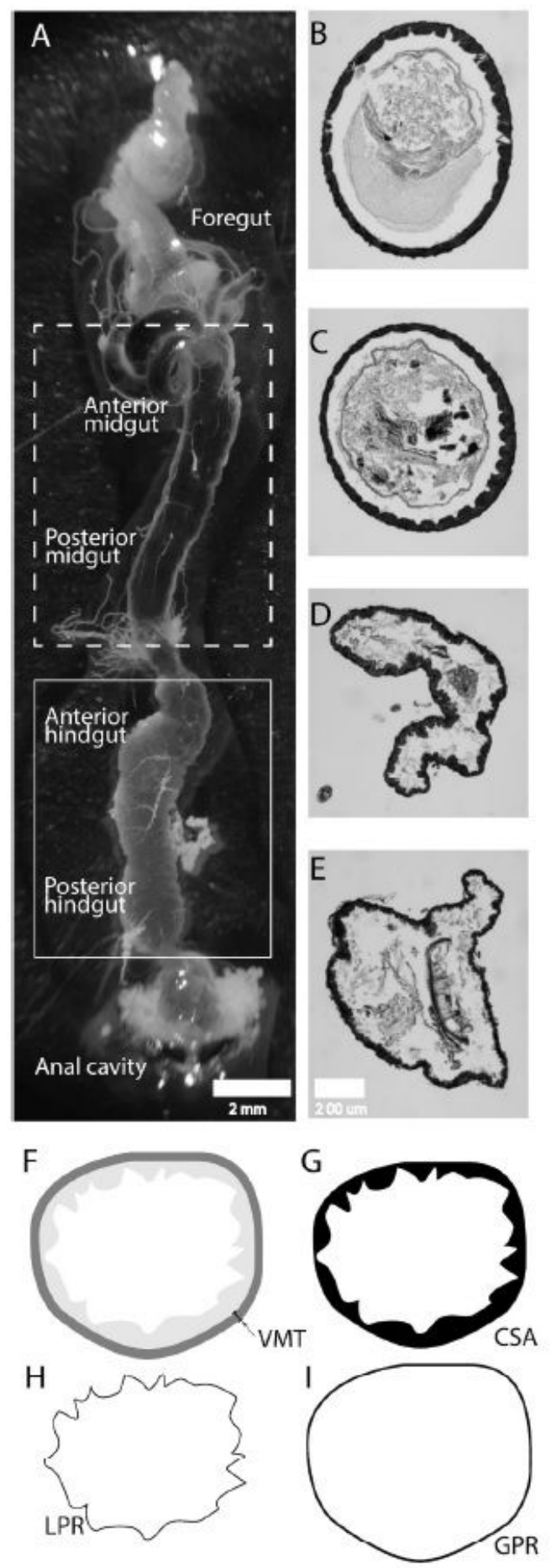

\section{Figure 1}

P. americana digestive tract and transverse section measurement schematic. Dissection of complete digestive tract (A) from 5th instar P. americana with the midgut (dashed box) and subcompartments and hindgut (solid box) subcompartments labeled. Exemplars of stained and imaged (100X magnification) transverse sections from lab reared P. americana anterior midgut (B), posterior midgut (C), anterior hindgut (D) and posterior hindgut (E). Diagram depicts the visceral muscle (dark gray), epithelial tissue 
(light gray) and lumen (white) in a stylized simplification of a transverse section (100x total magnification) of P. americana gut tissues (F). Masks (black) were generated from processed and imaged thin-sections and used to collect visceral muscle thickness (VMT; F), epithelial cross-sectional area $(C S A ; G)$, luminal perimeter (LPR; $H)$, and gut perimeter (GPR; I) measurements.

Anterior Midgut
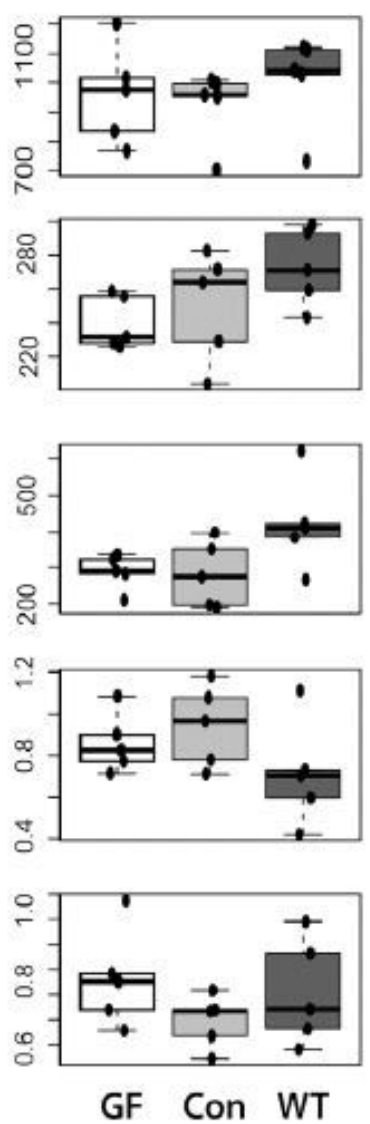

Posterior Midgut
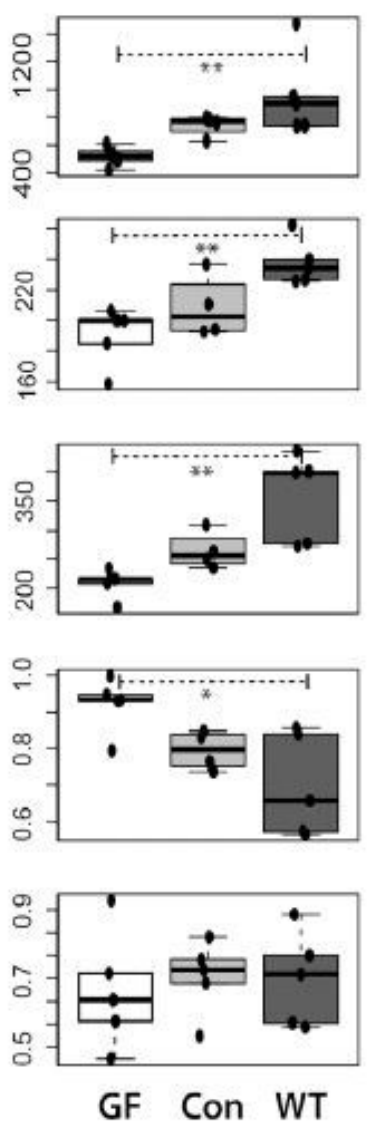

Anterior Hindgut
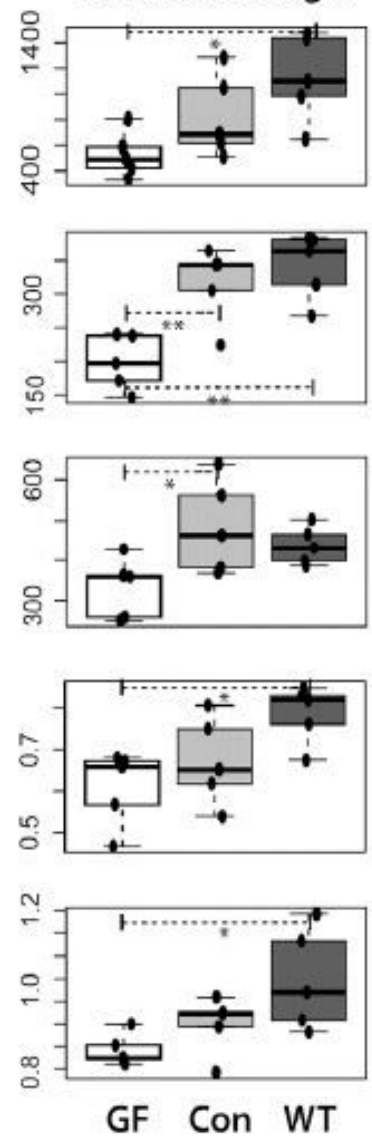

Posterior Hindgut

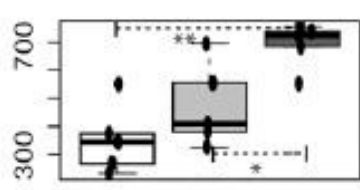

Epithelial Cross-Section Area $\left(\mu \mathrm{m}^{2}\right)$

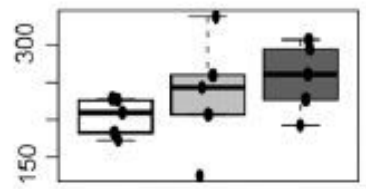

Gut Perimeter $(\mu \mathrm{m})$

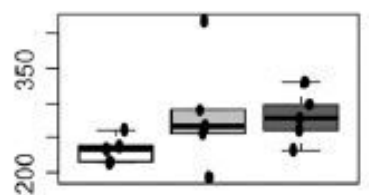

Lumen Perimeter $(\mu \mathrm{m})$

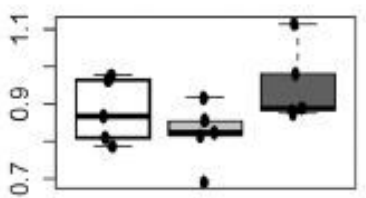

Gut Perimeterto-Lumen Perimeter Ratio

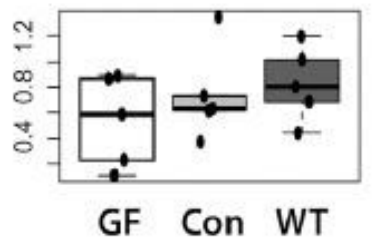

Visceral Muscle Thickness ( $\mu \mathrm{m})$

\section{Figure 2}

Exposure to normal gut bacterial community impacts gut subcompartment growth and development across several gut physiological measures. ANOVA was conducted on the average value of epithelial cross-sectional area (CSA), gut perimeter (GPR), luminal perimeter (LPR), gut perimeter-to-luminal perimeter ratio (a measure of luminal crypt depth) measurements and visceral muscle thickness (VMT) measurements from each insect. Boxplots represent first and third 500 quartiles, median, minimum and maximum values. Germ-free insects (GF, open fill), Single exposure to conspecific feces (Con, light grey fill); ad libatum access to conspecific feces and cohousing with nonsanitized insects under nonsterile conditions (WT, dark grey fill).

\section{Supplementary Files}

This is a list of supplementary files associated with this preprint. Click to download. 
- SupplementalMaterialsDataTables.xlsx

Page 5/5 